Article

\title{
Ground Subsidence Investigation in Fuoshan, China, Based on SBAS-InSAR Technology with TerraSAR-X Images
}

\author{
Yikai Zhu ${ }^{1,2}$, Xuemin Xing ${ }^{1,2, *}$, Lifu Chen ${ }^{1,3}$, Zhihui Yuan ${ }^{1,3}$ and Pingying Tang ${ }^{2,4}$ \\ 1 Laboratory of Radar Remote Sensing Applications, Changsha University of Science \& Technology, \\ Changsha 410014, China; zyk520cassiopeia@icloud.com (Y.Z.); lifu_chen@139.com (L.C.); \\ yuanzhihui@csust.edu.cn (Z.Y.) \\ 2 School of Traffic and Transportation Engineering, Changsha University of Science \& Technology, \\ Changsha 410014, China; tpy157@126.com \\ 3 School of Electrical and Information Engineering, Changsha University of Science \& Technology, \\ Changsha 410014, China \\ 4 Key Laboratory of Road Structure and Material of Ministry of Transport (Changsha), Changsha University of \\ Science \& Technology, Changsha 410014, China \\ * Correspondence: xuemin.xing@csust.edu.cn
}

Received: 11 April 2019; Accepted: 15 May 2019; Published: 17 May 2019

\begin{abstract}
Highways built on soft clay subgrade are more prone to subsidence due to the geotechnical characteristics of soft clay. Monitoring ground movements in this area is significant for understanding the deformation dynamics and reducing maintenance cost as well. In this paper, small baseline subset synthetic aperture radar interferometry (SBAS-InSAR) technique is exploited to obtain and investigate the time series ground surface deformation after the construction of a road embankment over soft clay settlement. Considering the important effect of temporal deformation models on the final accuracy of estimated deformation, both the linear velocity model and seasonal deformation model are utilized to conduct the comparative investigation of deformation time series. Two highways in Fuoshan, China-G1501 Guangzhou Belt Highway and Lungui Highway-were selected as the test area. Thirteen TerraSAR-X images acquired from October 2014 to November 2015 were analyzed. Comparative study based on two groups of analyses generated from the two models for both highways were conducted. Consequently, several feature points distributed near the two highways were analyzed in detail to understand the temporal evolution of the settlement. In order to evaluate the reliability of our measurements, the residual phase was analyzed to assess the modelling accuracy of the two models. In addition, leveling data were also used to validate the experimental results. Our measurements suggest that the seasonal model is more suitable for the test highways, with an accuracy of $\pm 3 \mathrm{~mm}$ with respect to the leveling results.
\end{abstract}

Keywords: InSAR; soft clay; time series; deformation; seasonal model

\section{Introduction}

Long-term monitoring of highways built on soft clay settlement after the construction of road embankments plays a significant role in preventing the long-term damage and economic losses induced from long-term subsidence and ensuring the project quality of highways [1]. In China, a large number of highways are built on soft clay under complicated geotechnical conditions, such as roads crossing agricultural paddies, lake areas, or valleys. Due to the geotechnical characteristics of large natural moisture content, high compressibility, low intensity, and unconsolidated structure, soft clay is more prone to ground subsidence under the action of traffic load. The stability control of soft clay subgrade 
has become one of the major technical challenges in the field of subgrade engineering [2]. G1501 and Lungui Highway are two examples of highways built on soft clay located in Fuoshan, Guangdong Province, China. Both highways play an important role in local transportation. Therefore, long-term temporal-spatial deformation monitoring of those highways is imperative and significant to understand the dynamics of ground movements and prevent potential traffic problems.

Traditional deformation monitoring methods, such as Leveling and GPS, have been proven to be highly precise and have been widely applied in highway deformation monitoring [3]. However, those methods have significant deficiencies of limited spatial coverage and expensive consumption of time and manpower, thus they are avoided in the application of deformation estimation for linear ribbon infrastructures including highways. Small baseline subset synthetic aperture radar interferometry (SBAS-InSAR) is an advanced InSAR technology proposed by Berardino and Lanari [4,5], which can obtain time series deformation results through extracting and processing the high coherence points in multi-scene differential interferometric images through a least squares method [6-8]. It can suppress temporal-spatial decorrelation of the traditional differential InSAR (D-InSAR) technology $[9,10]$ and has been widely applied in ground movements detection and deformation investigation induced by surface subsidence [11-13], volcanic eruption [14], glacier drift [15,16], earthquakes [17], and landslides [18-20].

Modeling the functional relationship between the deformation phase components and unknown parameters is a vital step in SBAS processing. Earlier study revealed that an accurate and reliable deformation model can not only improve the accuracy of deformation estimation, but also control the residual phase within an entire phase range, which affects the estimation of deformation parameters [21,22]. Considering this, in order to obtain more precise and reasonable deformation time series and better interpret the final time series subsidence, we conducted a comparative study based on two groups of analyses using traditional linear velocity model and seasonal model for both highways. SBAS-InSAR processing with 13 TerraSAR X images acquired from October 2014 to November 2015 is applied to obtain the unwrapped interferograms.

\section{Methodology}

\subsection{SBAS-InSAR Technology Based on the Linear Model}

The basic principle of SBAS-InSAR technology is to generate time series deformation based on a least square method, with the deformation maps generated by multi-single D-InSAR as the input observation dataset [23,24]. Firstly, as $\mathrm{N}+1$ SAR images obtained at dates $\left(t_{0}, \ldots, t_{n}\right)$, covering the same area, $M$ interferometric pairs can be produced following the inequality $\frac{N}{2} \leq M \leq \frac{N(N-1)}{2}$. Then, one SAR image can be selected as the super master image. The unwrapped phase at pixel $(x, r)$ in the $\mathrm{j}^{\text {th }}$ interferogram with the time period from dates $t_{A}$ to $t_{B}\left(t_{B}>t_{A}\right)$, can be expressed as [25]

$$
\begin{aligned}
& \delta \phi_{j}(x, r)=\phi_{B}(x, r)-\phi_{A}(x, r) \\
& \approx \frac{4 \pi}{\lambda}\left[d\left(t_{B}, x, r\right)-d\left(t_{A}, x, r\right)\right]+\frac{4 \pi}{\lambda} \frac{B_{\perp j} \Delta z(x, r)}{r_{j} \sin \theta_{j}}+\Delta \phi_{A P S}^{j}\left(t_{B}, t_{A}, x, r\right)+\Delta \phi_{r e s}^{j}(x, r)
\end{aligned}
$$

where $j \in(1, \ldots, M)$ is the order number of interferometric pairs. M is the total number of interferometric pairs. $(x, r)$ defines the SAR coordinates along range and azimuth direction, respectively. $\lambda$ is the radar wavelength ( $3.2 \mathrm{~mm}$ for X-band TerraSAR-X data); $d\left(t_{B}, x, r\right)$ and $\mathrm{d}\left(t_{A}, x, r\right)$ are line-of-sight (LOS) cumulative deformation, referred to as low-pass (LP) deformation component, at dates $t_{A}$ and $t_{B}$, respectively. $B_{\perp j}$ is the spatial baseline and $\Delta z$ represents the DEM residuals. $r_{j}$ represents the center range between the sensor and ground point. $\Delta \phi_{A P S}^{j}$ is the phase contribution related to atmospheric delay. $\Delta \phi_{r e s}^{j}$ is the residual phase, including phase noise, orbit error, and high-pass (HP) deformation component [22]. 
If the linear model is utilized to model the functional relationship between deformation and settlement rate, $d$ in Equation (1) can be expressed as

$$
d\left(t_{B}, x, r\right)-d\left(t_{A}, x, r\right)=\sum_{j=p+1}^{q} v_{j}\left(t_{j}-t_{j-1}\right)
$$

where $p$ and $q$ represent the index of master image at date $t_{A}$ and slave image at date $t_{B}$, respectively, for i-th interferometric pair. The unknown parameters here include elevation corrections $\Delta z$ and linear rates $v_{j}$ over different periods, which can be estimated through a least squares method. Obviously, the coefficient matrix of Equation (2) is a singular matrix. In order to solve the singular mathematical problem, a singular value decomposition (SVD) algorithm is used here [26]. The linear rates of each temporal unit can be estimated through the SVD algorithm. Consequently, the deformational component can be obtained by integrating the velocity of each period, and the final time series deformation results can be obtained [27-29].

\subsection{Seasonal Model}

In the seasonal model, the LP deformation is treated as a summary of linear and periodic components, which has been widely used to estimate the displacement affected obviously by seasonal effects (i.e., frozen soil) [30]. The LP deformation component in Equation (1) can be written as [31]:

$$
d(t, x, r)=\alpha_{1}(x, r) t+\alpha_{2}(x, r) \sin \left(\frac{2 \pi}{T} t\right)+\alpha_{3}(x, r) \cos \left(\frac{2 \pi}{T} t\right)
$$

where $t$ is the cumulative time related to the reference time and $T$ represents 365 days for a year. $\alpha_{1}, \alpha_{2}, \alpha_{3}$ are the unknown deformation parameters. The differential interferometric phase can be expressed as:

$$
\begin{aligned}
& \phi_{j}(x, r)=\alpha_{1}\left(t_{B}-t_{A}\right)+\alpha_{2}(x, r)\left(\sin \left(\frac{2 \pi}{T} t_{B}\right)-\sin \left(\frac{2 \pi}{T} t_{A}\right)\right) \\
& +\alpha_{3}(x, r)\left(\cos \left(\frac{2 \pi}{T} t_{B}\right)-\cos \left(\frac{2 \pi}{T} t_{A}\right)\right)+\frac{4 \pi}{\lambda} \frac{B_{\perp j} \Delta z(x, r)}{r_{j} \sin \theta_{j}}+\Delta \phi_{j, r e s}(x, r)
\end{aligned}
$$

The unknown parameters here include $\alpha_{1}, \alpha_{2}, \alpha_{3}$ and elevation corrections $\Delta z$, which are treated as constant coefficients over all temporal periods and can be estimated through a least square method, as discussed above. Consequently, the LP deformation of all the high coherence points can be obtained according to Equation (3) [32]. The HP deformation component is obtained by spatial-temporal filtering of residual phase component $\Delta \phi_{j, r e s}$, thus the time series deformation of all the high coherent points can be obtained [33,34]. The experimental flow based on SBAS and the two models is shown in Figure 1. 


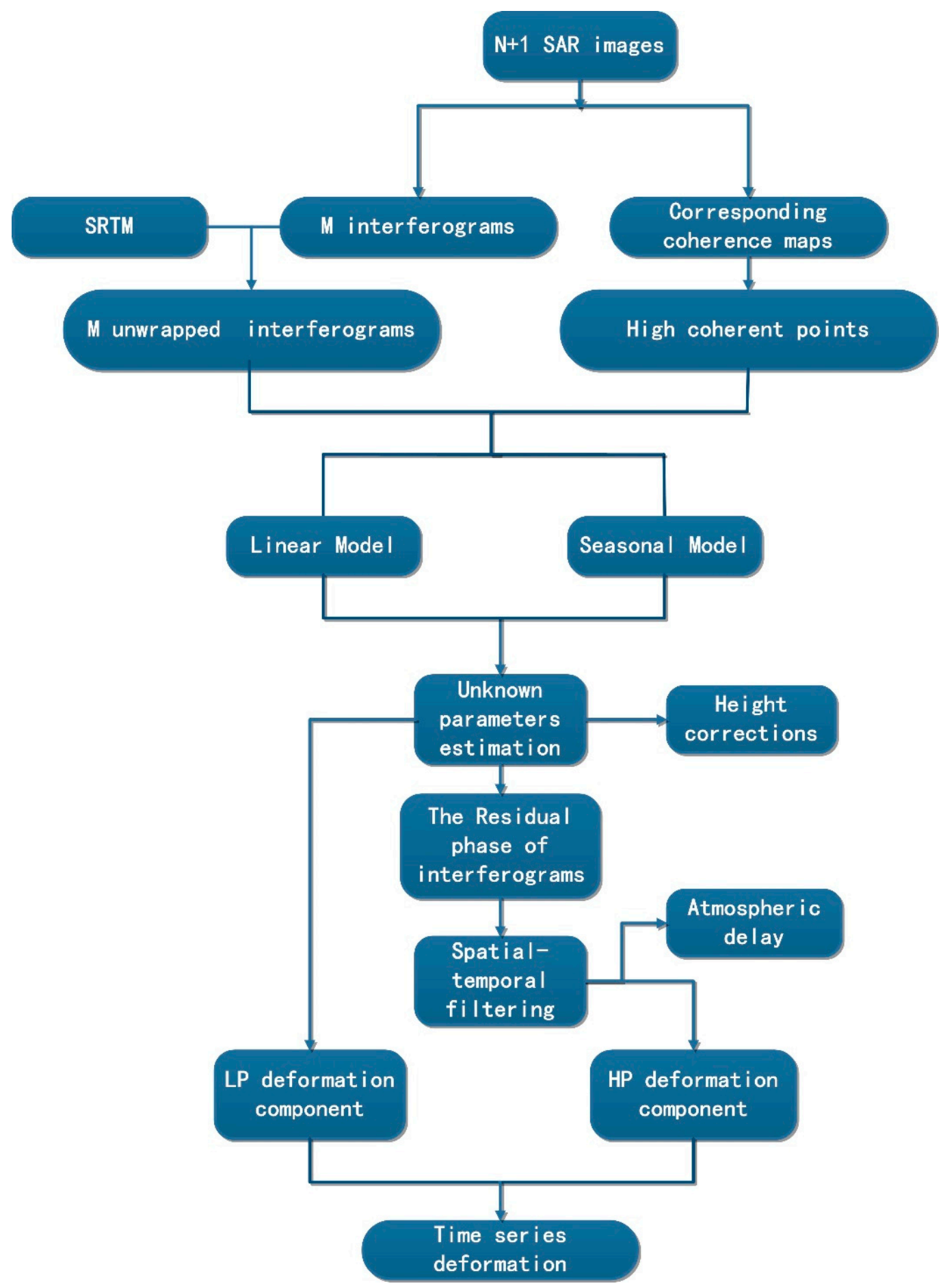

Figure 1. Experimental flow of small baseline subset synthetic aperture radar interferometry (SBAS-InSAR) based on two models.

\section{Experiment}

\subsection{Study Area}

Two highways in Fuoshan, Guangdong Province, namely Lungui Highway and G1501 Guangzhou belt highway, built on soft clay subgrade, are selected as test structures (Figure 2). Lungui Highway, as the significant transportation hub, connects G321 highway in the north and West Jiuhongqi Road in the south. With a total length of approximately $12 \mathrm{~km}$, Lungui Highway is one of the three major 
south-north transportation lines in Fuoshan. Its main road was opened to traffic in October 2014, constructed under the first-class highway standard and the urban roads standard. The subgrade was designed to be $60 \mathrm{~m}$ in width, with soft clay being the primary rock-soil substrate along the route. G1501 Highway, located in Shunde District, Fuoshan, is the south second ring part of the Guangzhou belt highway and was opened to traffic in 2010. The standard of two-way six-lane expressway with design of $100 \mathrm{~km} / \mathrm{h}$ is adopted for the whole route. The total length of the route is about $49.33 \mathrm{~km}$. Connected to the Guangzhou North stretch of Beijing-Zhuhai Expressway, G1501 Highway is a key transportation line diverting large traffic load from Guangzhou city transportation and strengthening the connection of surrounding urban agglomerations. According to the design criterion of these test highways, the permissible vertical post-construction subsidence is $30 \mathrm{~cm} / \mathrm{yr}$ for regular road segment, $20 \mathrm{~cm} / \mathrm{yr}$ for culvert, and $10 \mathrm{~cm} / \mathrm{yr}$ for bridges connections. According to the statistics of Fuoshan Transportation Bureau, the passengers flow volume of Shunde District, where the highways are located, is up to 2018.31 million people per kilometer, whereas the freights' flow using the test highways is approximately 654.64 million tons per kilometer in 2014. The huge traffic flow indicates the significant traffic situation of those two highways.

Both highways are located in delta alluvial plain, characterized by the presence of flat and low-lying surface of liquefiable sandy soil and underlying bedrock of granites and clay sand. The main geological component of the soft clay along the routes comprises muddy clay and silty clay, with characteristics of soft-plastic behavior. Due to the geotechnical characteristics of high natural moisture content, high compressibility, and low mechanical strength, the engineering properties of soft clay are extremely poor. Especially under the action of vibration load, soft clay is prone to engineering geological problems such as transverse slip, uneven settlement, and creep, accordingly imposing serious problems on the stability of subgrade and structures. Figure $2 \mathrm{c}$ shows the distribution of the water system around Lungui Highway and G1501 Highway. We can see the test highways are surrounded by three main rivers-Shunde, Tanzhou and Ronggui Channel, providing adequate underground water supply to the area. Due to the fast flow rate, Ronggui and Shunde Branch Channel play an important role in the underground aquifer in this area. The water level and volume in this area are greatly affected by precipitation and tide, according to the hydrological materials of this area.

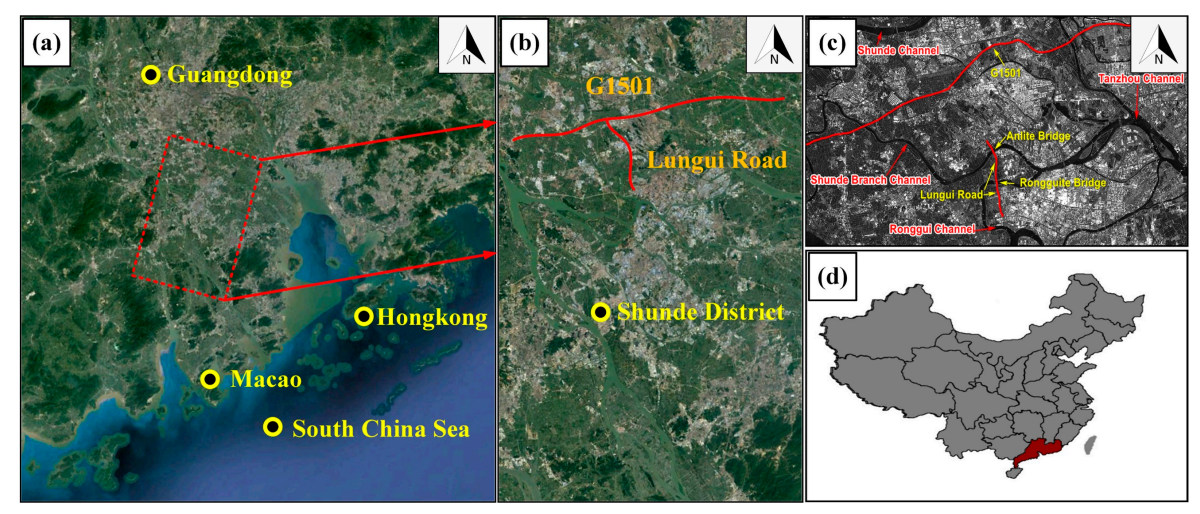

Figure 2. Study area featured at different scales: (a) Optical image. The red rectangle defines the spatial coverage of the TerraSAR-X images in our experiment; $(\mathbf{b}, \mathbf{c})$ Highway region of interest outlined in red solid lines; (d) Location in China.

\subsection{SAR Acquisitions and Data Processing}

A total of 13 repeat-pass TerraSAR X-band Stripmap descending images, provided by the German Aerospace Center, have been collected in this study. Their acquisition period covered from 27 October 2014 to 27 November 2015. The parameters of these TerraSAR-X images are listed in Table 1. The pixel spacing of selected images is $2.198 \mathrm{~m}$ along range direction, and $1.965 \mathrm{~m}$ along azimuth direction. Shuttle Radar Topography Mission Digital Elevation Model (SRTM DEM) with 30 m spatial resolution 
provided by National Aeronautics and Space Administration (NASA) is utilized as external topographic data [35].

Table 1. List of the interferometric pairs and their parameters with image number 6 as the master (orbit no.119).

\begin{tabular}{cccc}
\hline Image No. & $\begin{array}{c}\text { Acquisition Dates } \\
\text { (yyyy/mm/dd) }\end{array}$ & $\begin{array}{c}\text { Normal } \\
\text { Baseline (m) }\end{array}$ & $\begin{array}{c}\text { Temporal } \\
\text { Baseline (days) }\end{array}$ \\
\hline 0 & $2014 / 10 / 27$ & -126.22 & 242 \\
1 & $2014 / 11 / 18$ & 48.62 & 220 \\
2 & $2015 / 01 / 01$ & 122.99 & 176 \\
3 & $2015 / 02 / 14$ & -10.34 & 132 \\
4 & $2015 / 03 / 08$ & 15.94 & 110 \\
5 & $2015 / 05 / 13$ & -148.94 & 44 \\
6 & $2015 / 06 / 26$ & 0 & 0 \\
7 & $2015 / 08 / 09$ & -27.10 & 44 \\
8 & $2015 / 08 / 31$ & 57.39 & 66 \\
9 & $2015 / 09 / 22$ & -130.33 & 88 \\
10 & $2015 / 10 / 14$ & -36.83 & 110 \\
11 & $2015 / 11 / 05$ & -111.08 & 132 \\
12 & $2015 / 11 / 27$ & 111.41 & 154 \\
\hline
\end{tabular}

The interferometric processing work was accomplished by SARscape 5.2 software. The spatial and temporal baseline thresholds were set to be $130 \mathrm{~m}$ and 365 days, respectively. A total of 60 candidate interferometric pairs were generated for both tested highways. Figure 3 shows temporal baseline ( $x$ axis) and perpendicular baseline ( $y$ axis) of each selected time-adjacent interferometric pair. To remove the topographic phases, SRTM DEM was used to simulate interferometric phases subtracted from these interferograms. In order to maintain the resolution of highways, no multi-looking was conducted. Goldstein filter was utilized to further suppress the atmospheric phase. In addition, the interferograms were unwrapped with the minimum cost flow (MCF) method $[4,36]$. To improve the quality of coherent points, we used the triple threshold algorithm (the amplitude deviation index, the average coherence value, and intensity value) to detect the high coherence points automatically [37]. The coherence threshold of 0.6 and the amplitude deviation index of 0.4 was adopted to ensure a reliable distribution of high coherence candidates. The average coherence maps for the two test highways are shown in Figure 4. The lighter the color is, the higher the coherence is. From Figure 4, we can see that higher coherence is found in urban areas, mainly higher than 0.9 . After the coherent points selection, a total of 27,465 and 83,528 candidates were extracted for Lungui Highway and G1501 Highway respectively. After deleting low-quality interferometric pairs (i.e., with worse unwrapping phase, large orbit error and atmospheric delay), 42 high quality interferometric pairs for Lungui Highway and 49 for G1501 Highway were generated.
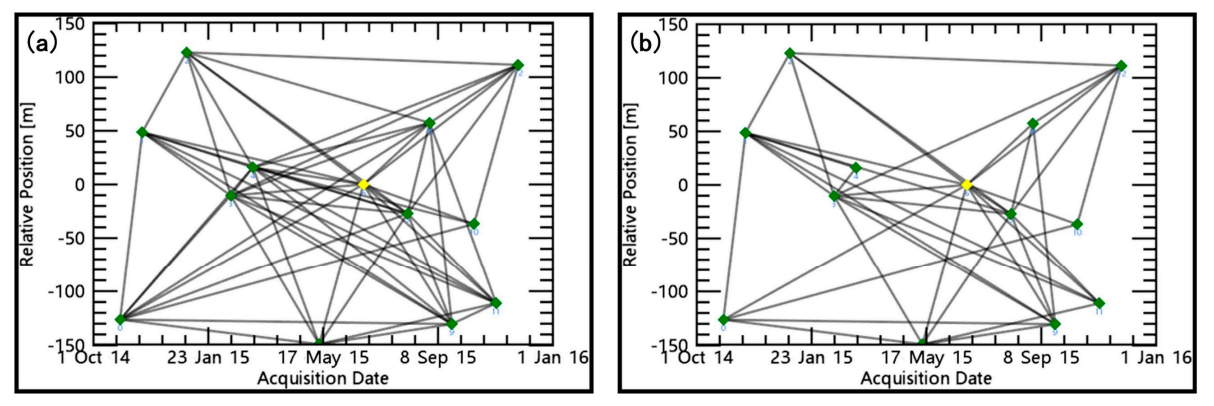

Figure 3. Spatial and temporal baselines of the interferometric pairs. ( $x$ axis represents the temporal baseline, $y$ axis represents the perpendicular baseline, and the yellow solid point represents the selected master image in our data stack) (a) Lungui Highway; (b) G1501 Highway. 

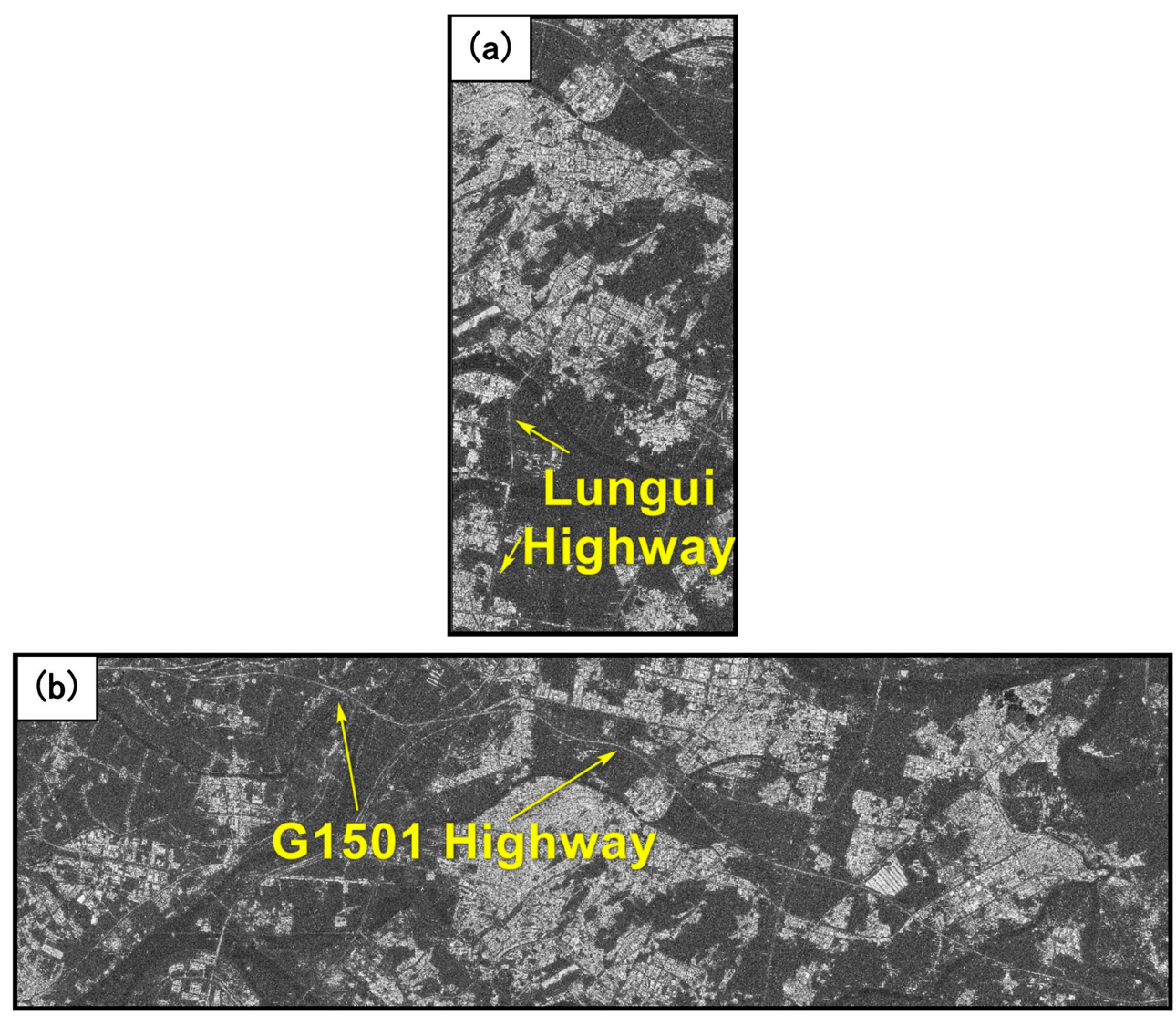

Figure 4. Average coherence maps. (a) Lungui Highway; (b) G1501 Highway.

\section{Results and Discussion}

\subsection{Lungui Highway}

Figure 5 shows the linear velocities comparison between the linear model and seasonal model. Figure 5a illustrates the mean value of all the temporal deformation velocities between every two time-adjacent SAR acquisitions obtained from the linear model. For comparison, the corresponding linear average velocity for the seasonal model is calculated through the LP deformation components acquired, according to Equation (3). As shown in Figure 5, linear model and seasonal model results show good agreement in spatial distribution, with the color ranging from light green to orange, and deformation rates generally ranging from $-35 \mathrm{~mm} / \mathrm{yr}$ to $5 \mathrm{~mm} / \mathrm{yr}$. It can be seen that the fast subsiding points densely distribute in the lower left corner and the upper right part for both models, with the velocity mainly ranging from $-25 \mathrm{~mm} / \mathrm{yr}$ to $-45 \mathrm{~mm} / \mathrm{yr}$. The maximum deformation rate is up to $-39 \mathrm{~mm} / \mathrm{yr}$ for the linear model. The main difference between the two images are two areas (see the area within solid rectangle A,B in Figure $5 \mathrm{a}$ ). The maximum subsidence rate detected at subsidence bowl $\mathrm{A}$ is $-38 \mathrm{~mm} / \mathrm{yr}$ from the linear model, whereas it is only $-24 \mathrm{~mm} / \mathrm{yr}$ from the seasonal model. In contrast, at the subsidence bowl B, the linear model shows smaller area, whereas the subsidence rate of the seasonal model is more serious, with a maximum value up to $-45 \mathrm{~mm} / \mathrm{yr}$. 

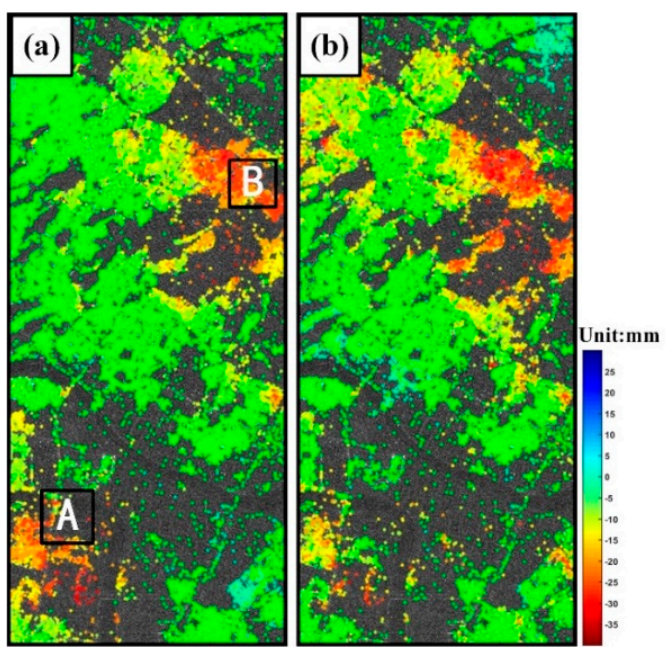

Figure 5. Average linear velocities of Lungui Highway. (a) Linear model; (b) Seasonal model.

Table 2. Comparison of experimental results between the linear model and seasonal model.

\begin{tabular}{ccccc}
\hline $\begin{array}{c}\text { Deformation } \\
\text { Model }\end{array}$ & $\begin{array}{c}\text { Subsidence } \\
\text { Increasing Period } \\
\text { (yyyy/mm/dd) }\end{array}$ & $\begin{array}{c}\text { Subsidence } \\
\text { Decreasing Period } \\
\text { (yyyy/mm/dd) }\end{array}$ & $\begin{array}{c}\text { Maximum } \\
\text { Subsidence } \\
(\mathbf{m m})\end{array}$ & $\begin{array}{c}\text { Maximum } \\
\text { Fluctuation } \\
\text { (mm) }\end{array}$ \\
\hline Linear & $2014 / 11 / 18-2015 / 08 / 31$ & $2015 / 08 / 31-2015 / 11 / 05$ & -71 & 67 \\
model & $2015 / 11 / 05-2015 / 11 / 27$ & $(2015 / 08 / 31)$ & 67 \\
Seasonal model & $2014 / 11 / 18-2015 / 06 / 26$ & $2015 / 06 / 26-2015 / 09 / 22$ & -66 & 62 \\
\hline
\end{tabular}
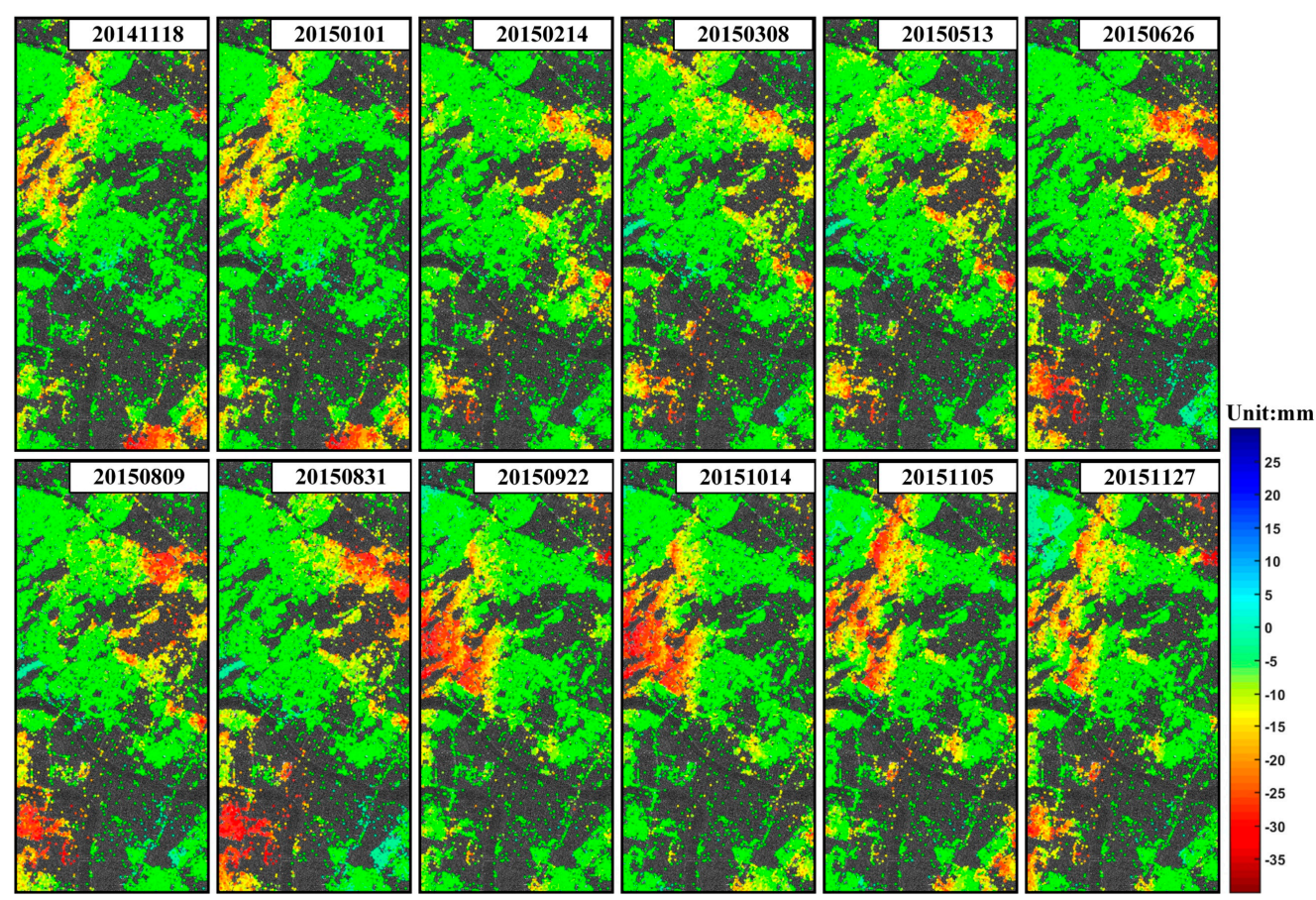

Figure 6. Time series deformation of Lungui Highway based on the linear model (referenced to 27 October 2014).

Figures 6 and 7 show the time series deformation generated from the linear model and seasonal model, respectively. From the spatial distribution, the results of the linear model and seasonal model are consistent, with two main obvious subsidence bowls in the upper right and lower left of the area, respectively. From the temporal variation, we can see both the results show serious fluctuation. 
The quantitative comparison of each highest oscillation, including subsidence increasing, subsidence decreasing period, the maximum subsidence, and fluctuations, are shown in Table 2. For the result of the linear model, the subsidence was increasing from 18 November 2014 to 31 August 2015, whereas a decreasing trend occurred from 22 September 2015. The peak subsidence occurred at 31 August 2015, with a magnitude of $-71 \mathrm{~mm}$. The overall deformation mainly distributes within the range of -20 to $0 \mathrm{~mm}$. For the result of the seasonal model, similar subsiding increasing trend can be found until 25 June 2015. However, from 26 June 2015 to.22 September 2015, the seasonal results showed an obvious jump in subsidence reduction, with the maximum subsidence recovery of $32 \mathrm{~mm}$. From October 2014 to November 2015, another subsiding period started. The key reason for this temporal periodical variation is supposed to be related to the local hydrogeological conditions discussed as follows.

From Figure 2c, we can see the densely distributed ponds along this route (small dark rectangles). Most of those areas are breeding ponds, near Ronggui Channel and Shunde Branch Channel. According to the in situ investigation, the ground water of the test area can be mainly divided into four layers: The first layer is stagnant water contained in the filled soil layer, receiving recharge from meteoric water, surface river water, and breeding ponds, and discharging by evaporation; both the second and third layer are porewater with the characteristic of pressure-bearing, contained in the fine sand layers. It receives the recharge of vertical river and lateral permeability water; the fourth ground water layer is bedrock fracture water with very low water flow, contained in three rock layers under the ground surface of the test highway. As the in situ survey shows, the shallow groundwater has a certain hydraulic connection with the surface stream, thus the groundwater level is highly affected by season. According to the hydrological materials of this area, the maximum variation of upper side groundwater level is up to 1 meter. Figure 8 demonstrates the simulated groundwater mechanical structure of this area.
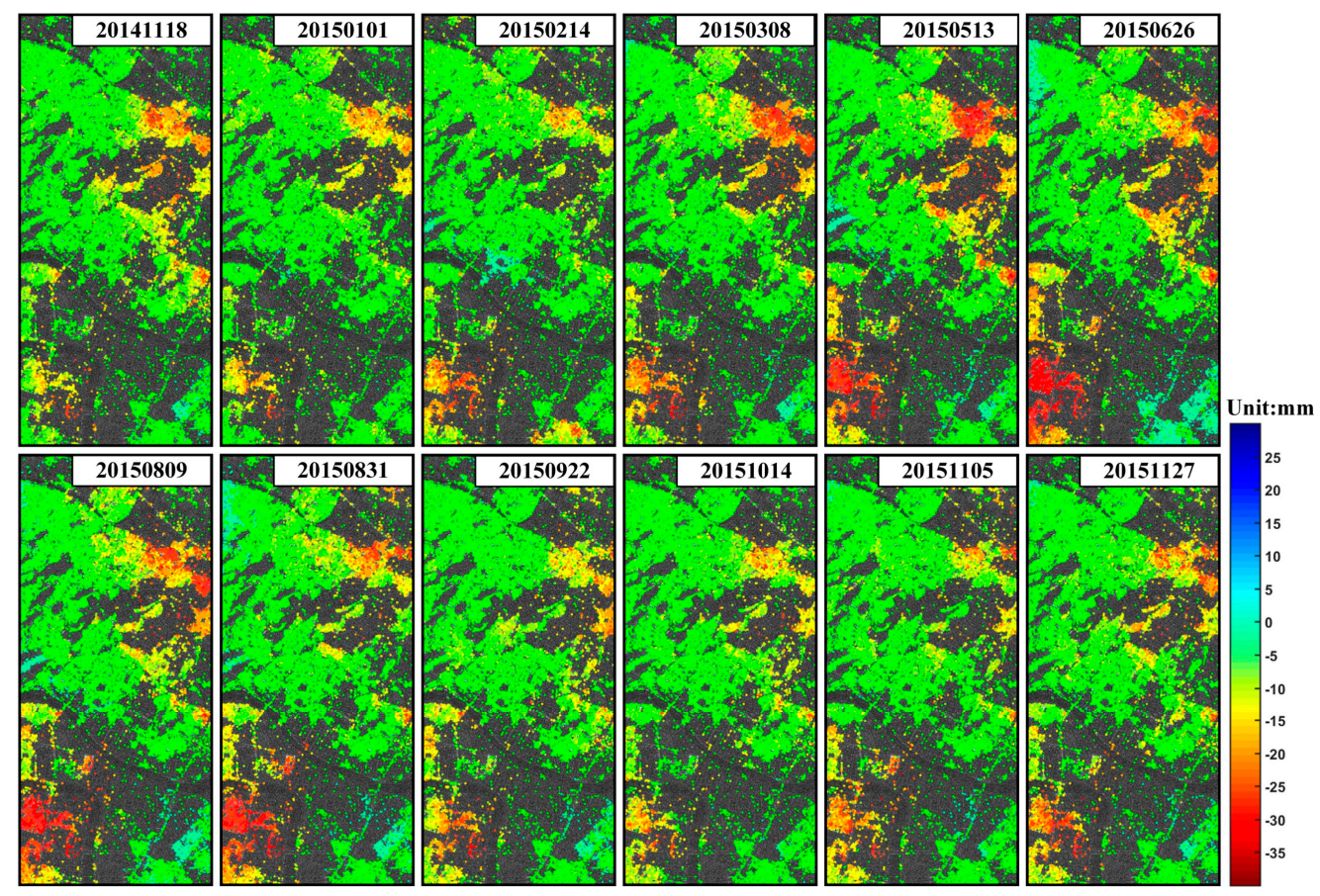

Figure 7. Time series deformation of Lungui Highway based on the seasonal model (referenced to 27 October 2014).

Aquifer is the main body of saturated rock in the shallow soft clay layer, where water can flow easily. All of aquifers are permeable. The storage of flowing water in the aquifer is greatly affected by season $[38,39]$. Groundwater flows through aquifers at a rate of 50 feet or inches per century (depending on the permeability). However, regardless of the speed, water will eventually be released or left in an 
aquifer. Each aquifer has a recharge and discharge area, respectively, and the amount of water stored in the aquifer reflects the altitude of its groundwater level. If the water inrush quantity is lower than the natural displacement, the groundwater level and the storage of aquifers will decrease [40,41]. The water level of an aquifer is usually highly sensitive to seasonal recharge, so it usually decreases in summer or in dry years [42,43]. In summer, high temperature promotes the evaporation of flowing water in the shallow aquifer, thus leads to the decreasing of aquifer volume. In contrast, as the temperatures drop gradually in winter, the evaporation of flowing water in the shallow aquifer is suppressed, thus the subsiding decreasing phenomenon is supposed to occur. As Figure 8 shows, from June 2015, the temperature starts to drop gradually, with an accumulated decrease of $10^{\circ} \mathrm{C}$ until December. Another important reason for this seasonal deformation variation is supposed to be related to the increasing rainfall during June to December. According to the precipitation records of Fuoshan (see Figure 9), affected by the combined upper trough and bottom vortex, increasing rainfall appeared since 27 June 2015. The average rainfall amount is $127.3 \mathrm{~mm}$ in Fuoshan city, with $100-250 \mathrm{~mm}$ at $65 \%$ automatic stations recorded, and $250 \mathrm{~mm}$ at Shunde automatic station. Due to the increase of rainfall, both water amount in the shallow aquifer and the discharge in nearby water system are significantly increased correspondingly. With accelerated flow speed, ground water in the aquifer of soft clay expanded due to the impact of precipitation and supply from the surrounding water system, consequently inducing considerable uplift phenomena.

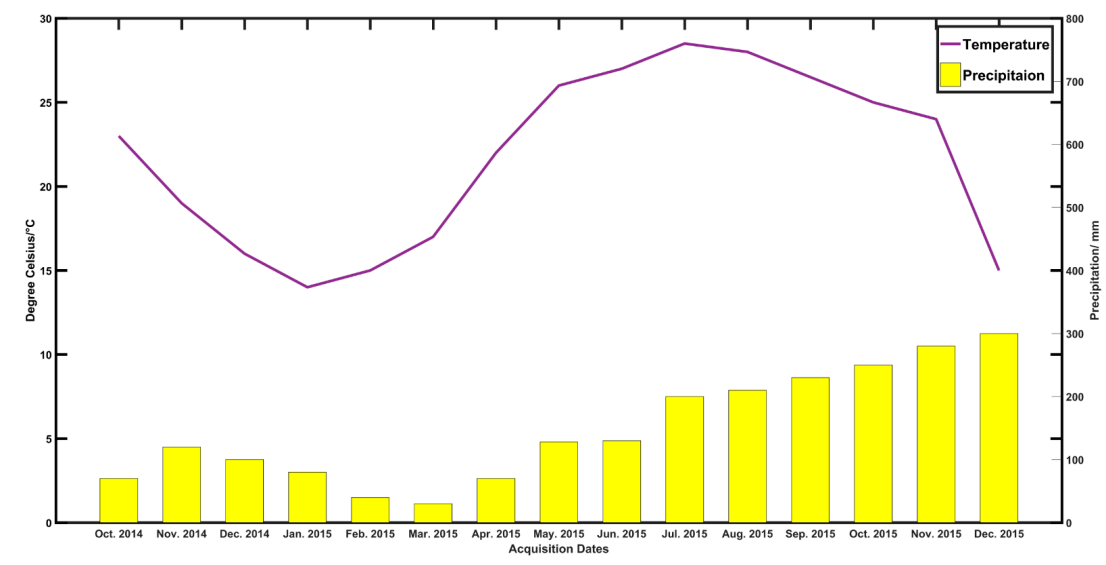

Figure 8. The temperature and precipitation of Fuoshan city (from October 2014 to December 2015).

In order to further analyze the time series variation characteristics of high coherence point deformation, three feature points A, B and C (their positions are shown in Figure 9) are selected to be analyzed. As shown in Figure 9, point A is located at the junction of Lungui Road and Junye Road. From the comparison, we can see that seasonal model results show generally periodic variation trend, with accumulated peak subsidence of $-49 \mathrm{~mm}$ in Jun 2015 (Figure 10a). However, from June 2015 to October 2015, significant uplift of $36 \mathrm{~mm}$ occurred on this point. As shown in our aforementioned analysis, with the increase of rainfall, the underground water quantity increased considerably, thus inducing the uplift phenomena. Comparatively, similar periodic deformation trend is detected from the linear model results. The difference is that the peak subsidence occurred in August 2015 and the cumulative deformation reached up to $-32 \mathrm{~mm}$, with a lower maximum fluctuation of $17 \mathrm{~mm}$ compared to that of seasonal model. In August and November 2015, a slight jump occurred, with the jump range of about $22 \mathrm{~mm}$. Point $B$ is located in residential areas at the junction of West Xinliang Road and South Fuoshan First Ring Extension Line. Point $C$ is located next to Shunde Branch Channel and Anlite Bridge. From Figure 10b,c, we can see the deformation trends at both point B and C perform similar variations, with a typical periodic evolution characteristic. From the seasonal model results, the accumulated maximum subsidence on point $B$ is up to $-38 \mathrm{~mm}$ and the maximum seasonal fluctuation is $23 \mathrm{~mm}$. 


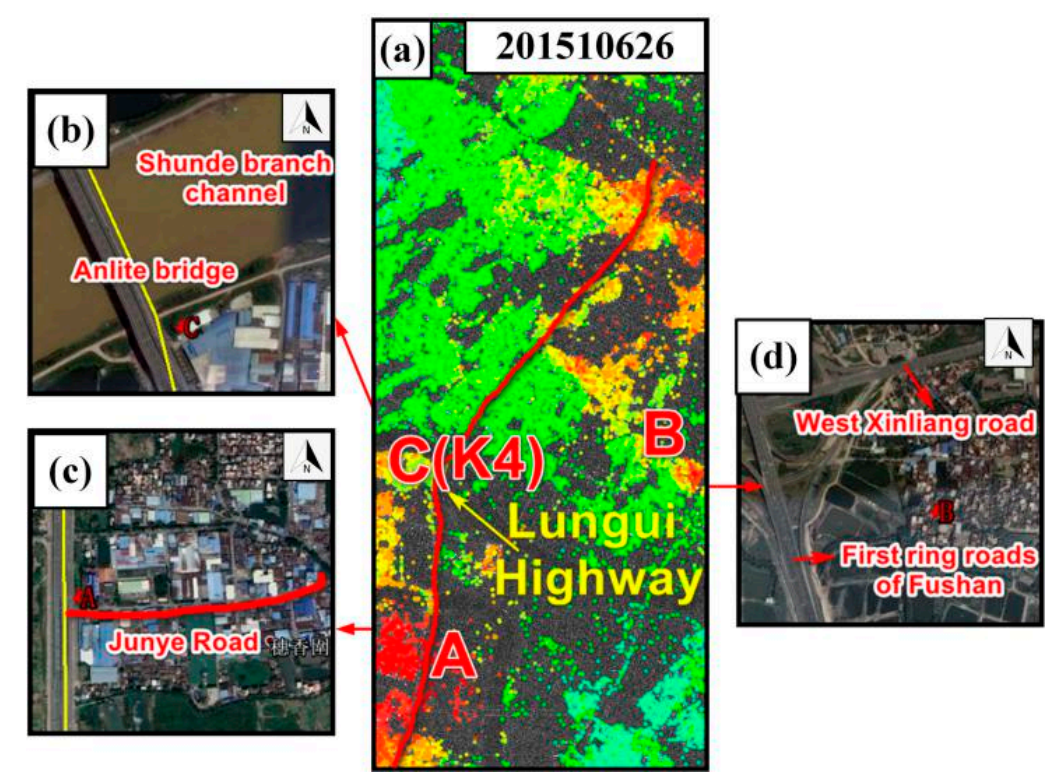

Figure 9. Locations of typical feature points A, B, C. (a) Deformation map over period of 27 October 2014 to 27 November 2015 in SAR coordinate system. (b-d) Locations of Point A, C (Levelling point K4) and B in Google Maps, respectively.
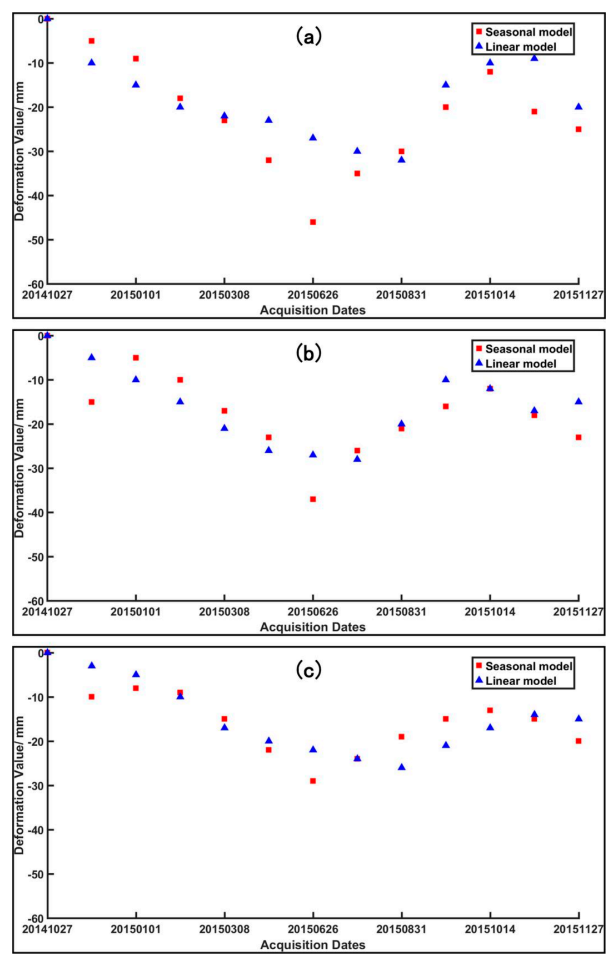

Figure 10. Time series deformation on point A, B, C in Lungui Highway. ( $x$ axis defines the acquisition data of TerraSAR-X images, $y$ axis defines the deformation values) (a) Point A; (b) Point B; (c) Point C (K4).

In order to show more clearly the distribution of each deformation magnitudes in Lungui Highway, the quantitative comparison of the deformation magnitude distribution is specially selected for illustration over the period of 27 October 2014 to 27 November 2015 (Figure 11). From the quantitative analysis, $80 \%$ of coherent points are within the range of -30 to $0 \mathrm{~mm}$ for linear model, whereas $77 \%$ are for the seasonal model. 


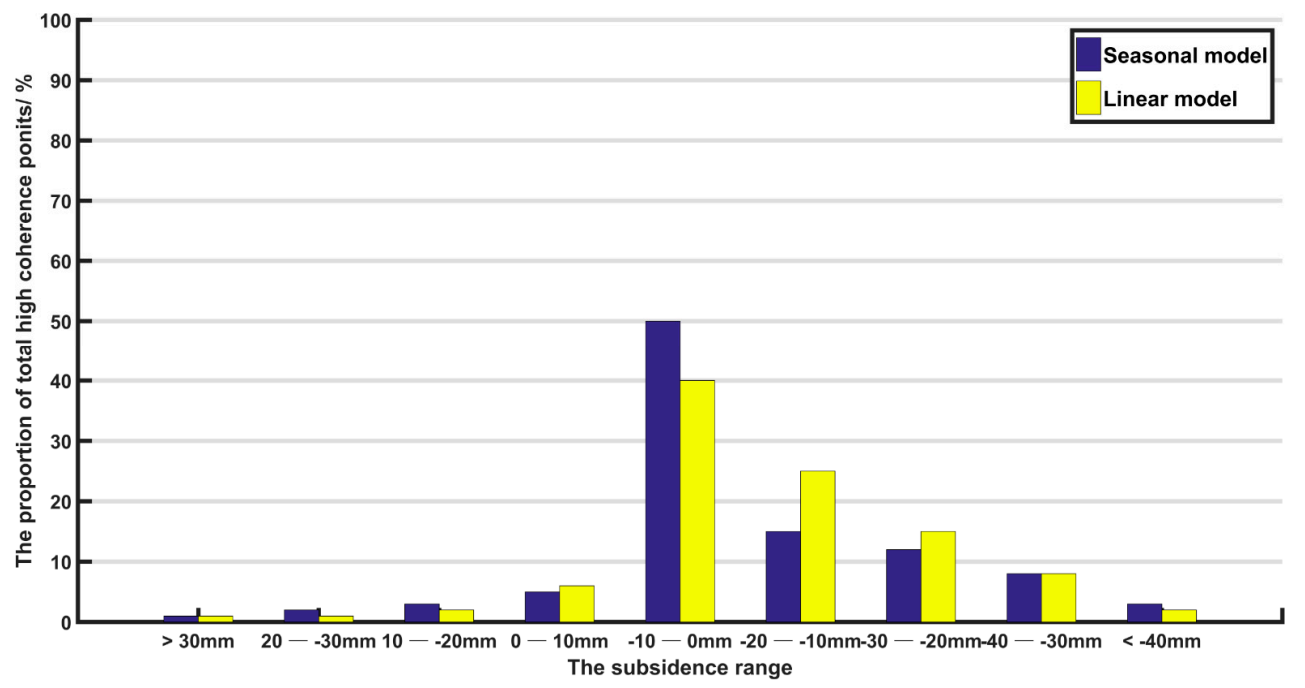

Figure 11. The magnitude distribution of settlement points in Lungui Road from 27 October 2014 to 27 November 2015 ( $x$ axis defines each deformation interval; $y$ axis defines the proportion of total high coherence points).

\subsection{G1501 Highway}

During our data processing for the G1501 Highway area, unexpected orbital errors appeared in most interferograms. As shown in Figure 12, the original generated deformation map is obviously disturbed with orbital signal (the fringes ranging from green to red color in Figure 12b). The second-order polynomial fitting method is used here to remove the orbital error. As shown in Figure 12c, after simulating and deleting the linear orbital error component, the deformation signal has been extracted, with several obvious subsiding areas [44].

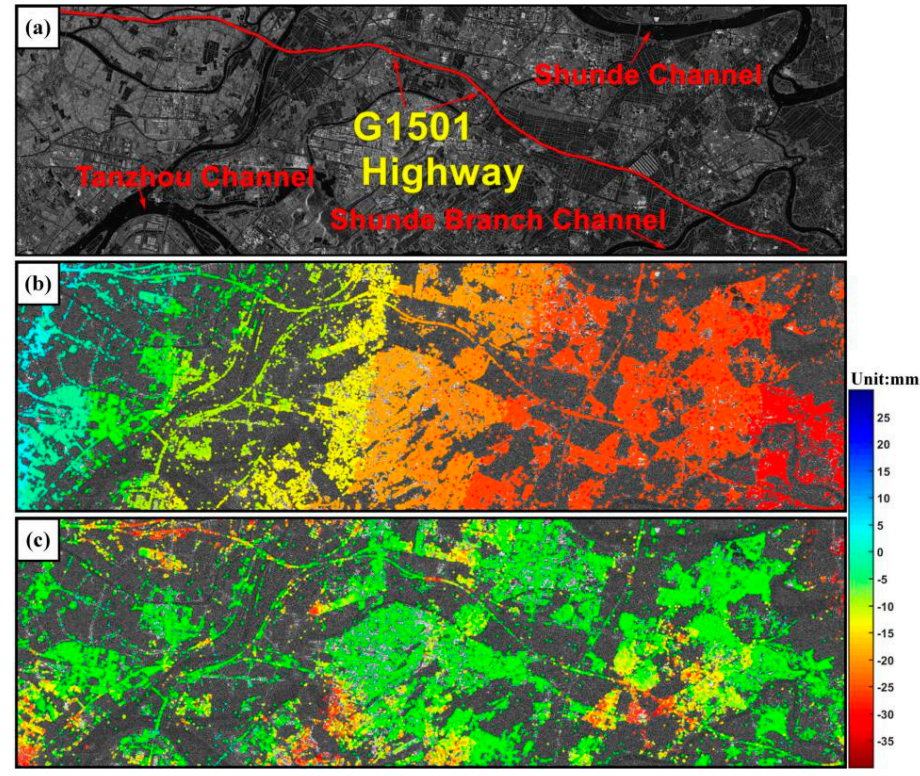

Figure 12. (a) The amplitude map over G1501 Highway; (b) The deformation map with obvious orbital error (27 October 2014 to 26 June 2015); (c) Corrected deformation map without orbital error (27 October 2014 to 26 June 2015). 


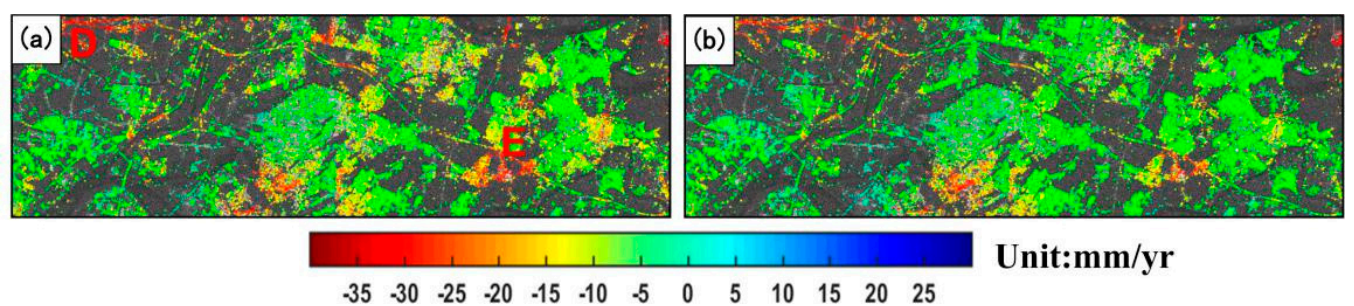

Figure 13. The average velocity maps over G1501 Highway generated by two models. (a) Linear model result; (b) Seasonal model result.

Figure 13 shows the average linear velocities comparison for two models over G1051 Highway. As shown in Figure 13, the linear model and seasonal model demonstrate good agreement in spatial distribution, with the deformation velocity generally ranging from -27 to $-8 \mathrm{~mm} / \mathrm{yr}$ and the color ranging from light green to orange yellow. The large subsidence points are mainly concentrated in the upper left and bottom right part of the images, with the maximum velocity up to $-63 \mathrm{~mm} / \mathrm{yr}$ detected from linear model and $-57 \mathrm{~mm} / \mathrm{yr}$ from seasonal model.

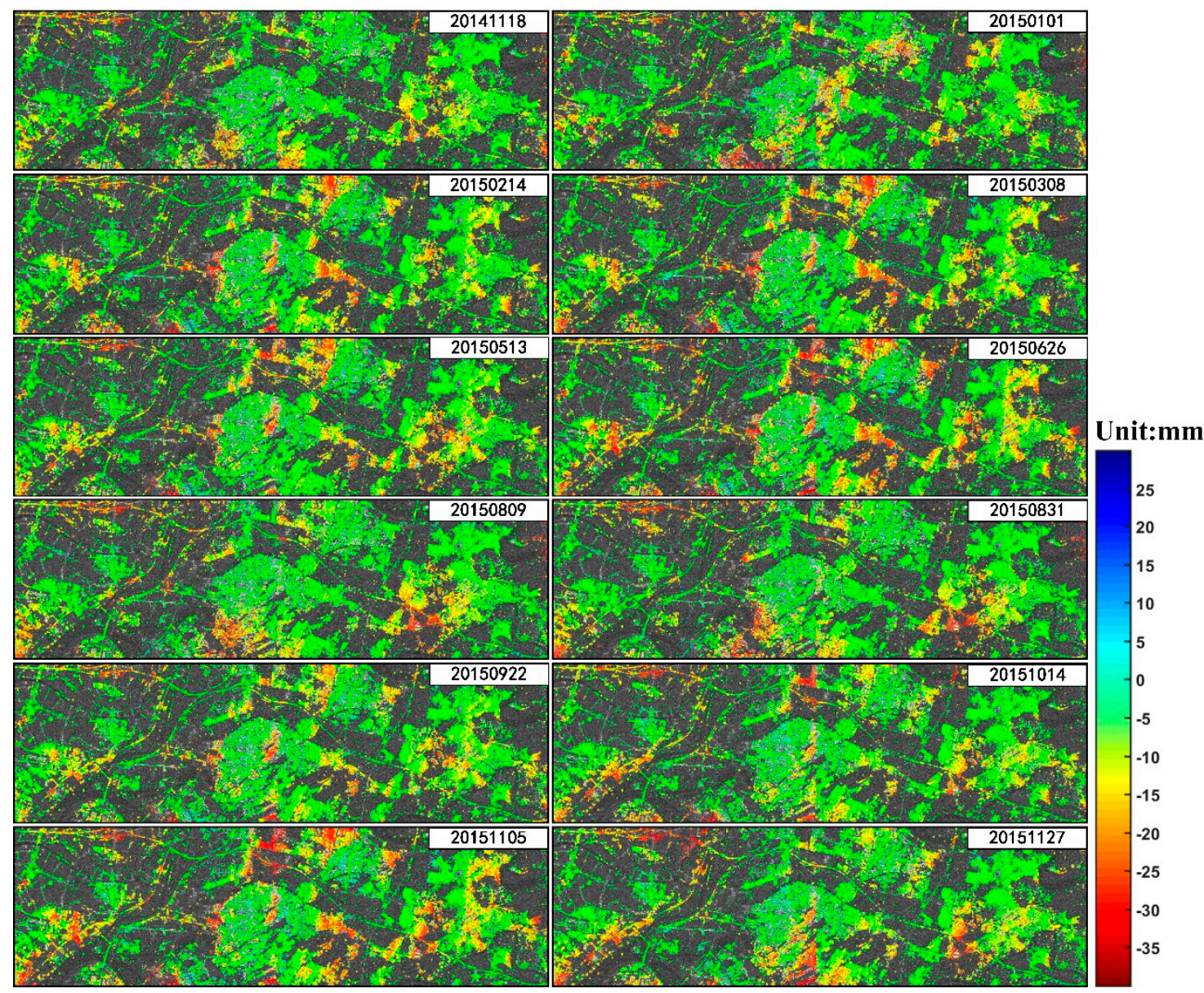

Figure 14. Time series deformation of G1501 Highway based on the linear model (referenced to 27 October 2014). 


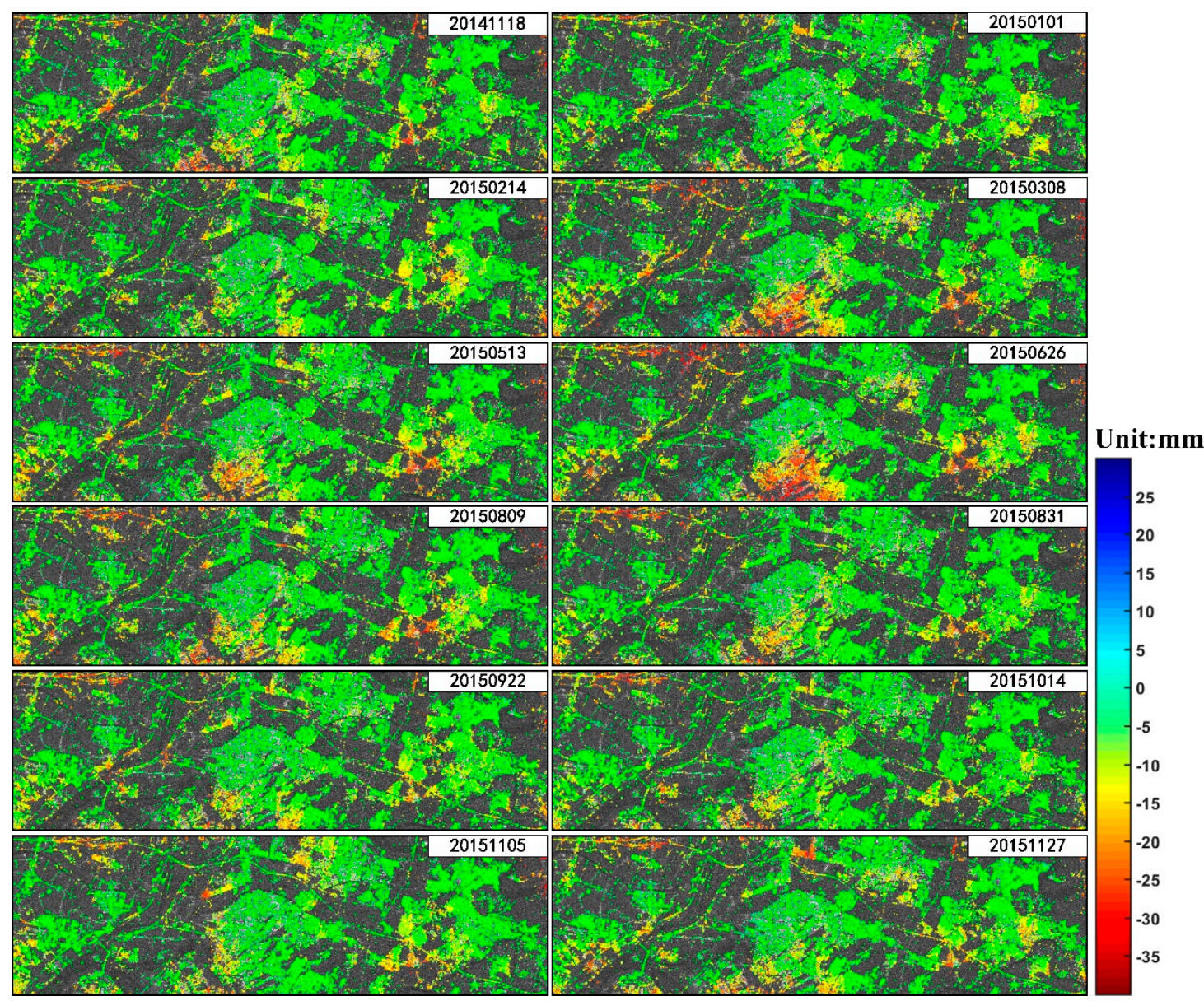

Figure 15. Time series deformation of G1501 Highway based on seasonal model (referenced to 27 October 2014).

The time series deformation results of G1051 area obtained by the linear model and seasonal model are shown in Figures 14 and 15, respectively. From Figure 14, no obvious discipline of the temporal deformation variation can be found, and the temporal evolution over this stretch of highway performed relatively smoothly. From January 2015 to August 2015, the subsidence is slightly increasing, whereas from August 2015 to November 2015, the subsidence showed a slowly decreasing fluctuation, with the maximum cumulative deformation of $-65 \mathrm{~mm}$ in August 2015. In contrast, the results generated by the seasonal model showed a more obvious periodic fluctuation. The subsidence gradually increased from December 2014 to June 2015, with the peak value of $-67 \mathrm{~mm}$ in June 2015, and began decreasing from June 2015. The maximum recovery of subsidence is $21 \mathrm{~mm}$. Since G1501 Highway is under similar geotechnical environment with Lungui Highway, the reasons for this typical seasonal variation are supposed to be related to the hydrogeological conditions and climate factors including precipitation and temperature. From the spatial distribution, deformation generated by both models are generally consistent, with the obvious subsiding bowls distributed in the middle and lower parts of the map.

Figure 17 demonstrates the time series deformation of feature point $\mathrm{D}$ and $\mathrm{E}$ (the corresponding locations in deformation map and Google Maps are shown in Figure 16). Point D was located at the junction of N59 rural road and G1501 Highway. From Figure 16 we can see that the linear model results show a slow subsiding with slight fluctuations, whereas the seasonal model result presents obvious periodic variations. In June 2015, the maximum cumulative deformation of $-48 \mathrm{~mm}$ occurred. Similar characteristics can be found at point E, as shown in Figure 17b. For the periods of February 2015 to June 2015 and October 2015 to November 2015, the deformation was gradually increasing, with the maximum magnitude of $-32 \mathrm{~mm}$. From June to October 2015, apparent subsidence recovery occurred. 
As shown in Figure 16, both point $\mathrm{D}$ and $\mathrm{E}$ were located in the suburbs, with fish ponds surrounding them. The increase of rainfall and decrease of temperature may suppress the subsiding of soft clay.

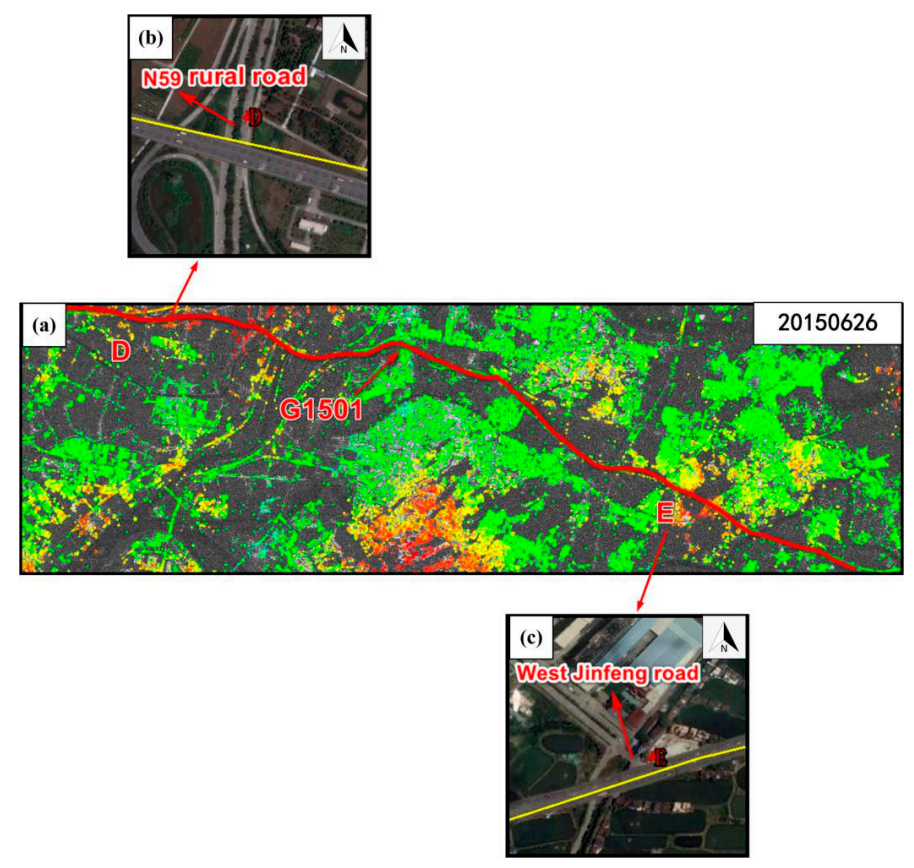

Figure 16. Locations of feature points D and E. (a) Deformation map obtained by linear model 27 October 2014, Table 2015, over G1501 Highway. (b) Location of Point D in Google Maps; (c) Location of Point E in Google Maps.
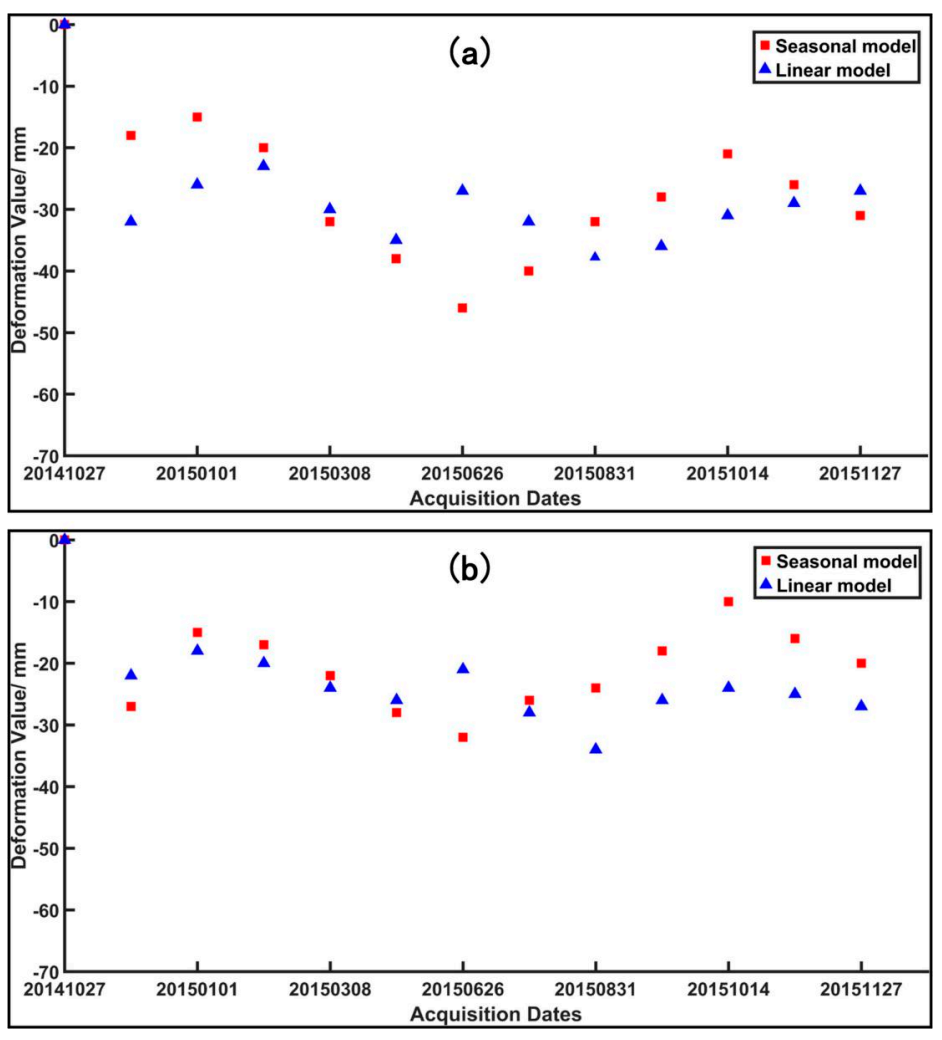

Figure 17. Time series deformation of feature point $D, E$ ( $x$ axis defines the acquisition data of TerraSAR-X images, $y$ axis defines the deformation values); (a) Point D; (b) Point E. 


\subsection{Accuracy Assessment}

In order to verify the reliability of the results obtained through two models, we calculated the residual phase for all the coherent points. The average residual phase for each interferogram is shown in Figure 18. The overall magnitude of the residual phase for both cases is less than $1 \mathrm{rad}$, indicating both the linear model and seasonal model have good accuracy for time series deformation modeling, thus are reliable in the application of deformation monitoring in soft clay subgrade areas. For Lungui Highway, the root mean square (RMS) of the residual phase obtained by seasonal model is $1.8 \mathrm{rad}$, whereas the linear model is $2.1 \mathrm{rad}$, with a $14 \%$ improvement. For G1501, the mean square root of the residual phase acquired by seasonal model is $2.7 \mathrm{rad}$, whereas the linear model is $3.4 \mathrm{rad}$, with a $20 \%$ improvement. Both figures reveal that the seasonal model shows better modelling accuracy. Correspondingly, the seasonal model is more highly recommended for test highways in this paper.
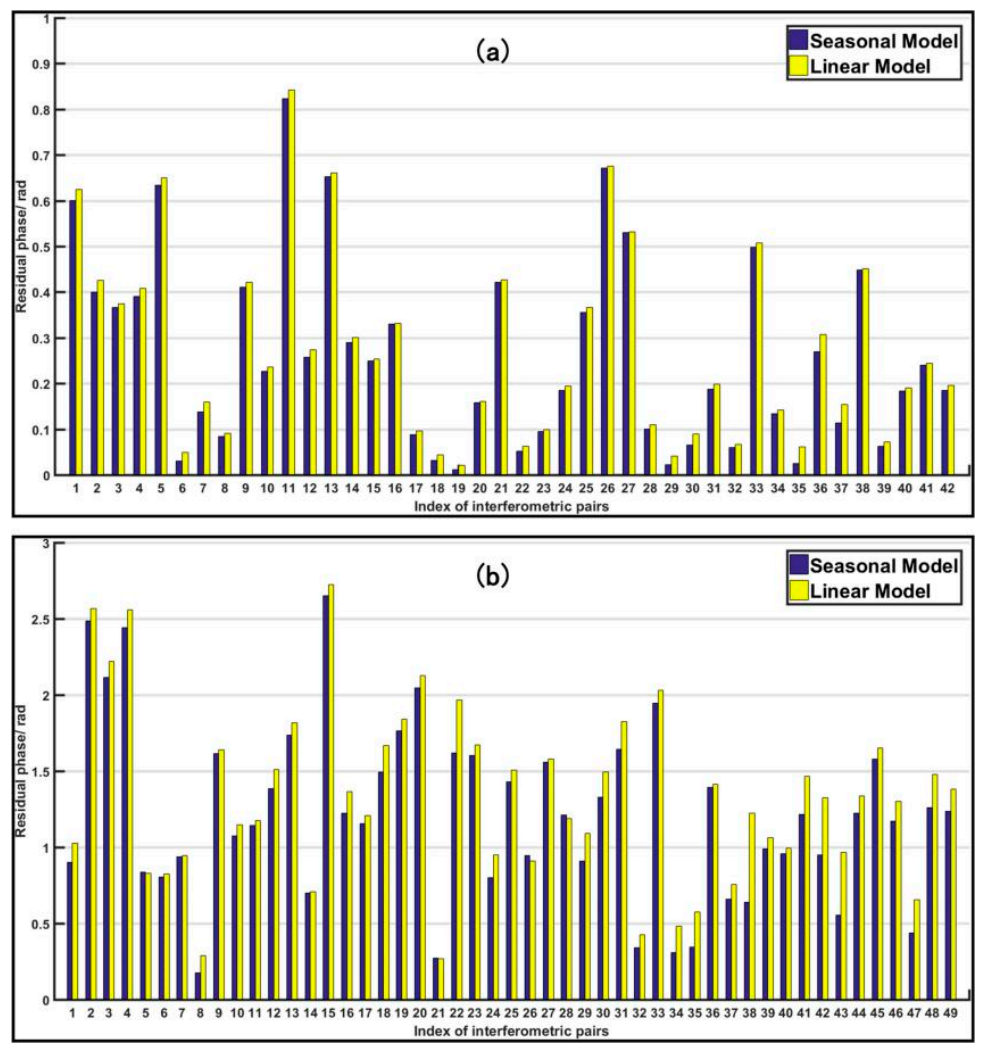

Figure 18. The residual phase comparison. ( $x$ axis represents the index of interferograms; $y$ axis represents the mean residual phase for all coherent points.) (a) Lungui Highway; (b) G1501 Highway.

In addition, ground leveling measurements over the period of October 2014 to March 2015 were collected to estimate the external accuracy of our experiment. The location of leveling point K4 is shown in Figure 9. Figure 19 shows the time series results generated by both models at K4 compared to that of leveling. It can be obviously seen that both models show good consistency with the leveling measurements, indicating the SBAS technology is feasible for time series deformation monitoring of highways built on soft clay subgrade. The root mean square error (RMSE) for linear model results is estimated to be $\pm 4 \mathrm{~mm}$, whereas, for seasonal model, this is $\pm 3 \mathrm{~mm}$. From our quantitative comparison, the accuracy of the seasonal model is slightly higher than that of the linear model. Considering both the accuracy evaluated through the residual phase and the comparison with leveling measurements, the seasonal model is more highly recommended here for time series investigation in our case study. 


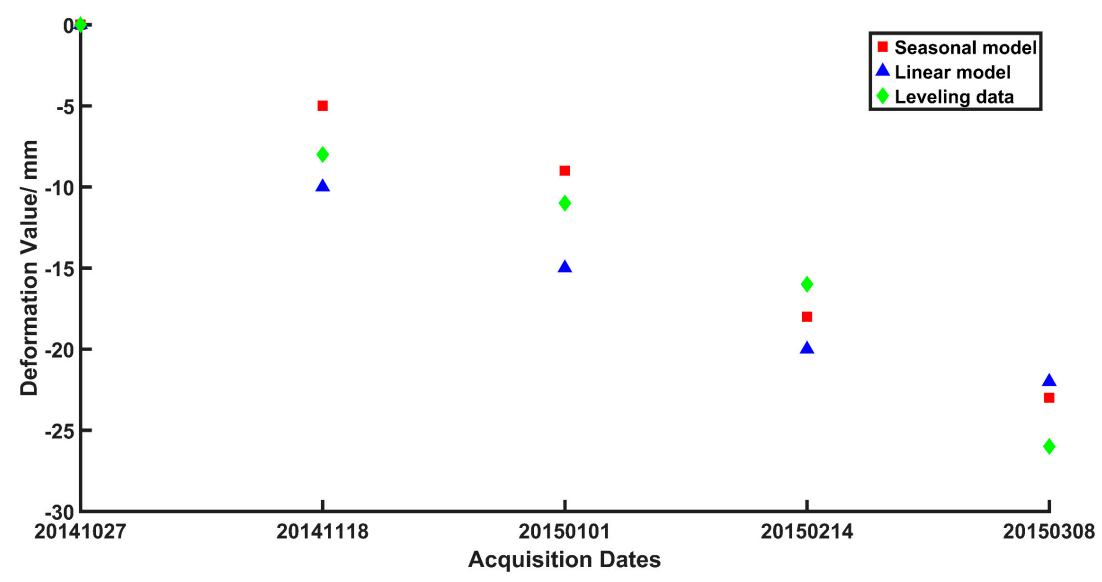

Figure 19. Time series deformation results compared with leveling measurements on $\mathrm{K} 4$ (the location is shown in Figure 9).

\section{Conclusion}

A case study based on SBAS-InSAR technology and TerraSAR X imaginary is presented to investigate the long-term deformation for highways built on soft clay subgrade after the road construction over a 13-month period from October 2014 to November 2015. A comparative study of the linear model and seasonal model were conducted. The deformation parameters and corresponding time series deformation were estimated for both models on the two highways, respectively.

After our comparative analysis, similar spatial distribution of subsidence and temporal seasonal fluctuation can be found in both models. The main difference between the two groups of measurements generated by the two models is that the maximum subsidence occurred in August 2015 through the linear model, whereas, in June 2015, through the seasonal model. According to the seasonal model measurements, the most obvious subsidence was up to $-65 \mathrm{~mm}$, whereas the subsidence recovery effect in November 2015, with magnitude, accumulated to $23 \mathrm{~mm}$. The reasons suggested for this seasonal effect are related to the hydrogeological conditions and external climatic factors, including temperature and precipitation. We also conducted concrete deformation monitoring and analysis over typical ground features.

To assess the accuracy for the two groups of case study measurements, residual phase and ground leveling deformation are utilized to evaluate the modeling and external accuracy, respectively. Compared to the linear model, the RMS of residual phase for the seasonal model was improved with $14 \%$ and $20 \%$ for Lungui Highway and G1501 Highway, respectively. The external accuracy evaluated by leveling measurements was improved from $\pm 4 \mathrm{~mm}$ to $\pm 3 \mathrm{~mm}$ for Lungui Highway. Consequently, seasonal model is more highly recommended in our case study.

The major deficiency of this case is that only limited leveling measurements are available. The two models utilized in this experiment are pure mathematical empirical models, without specific physical parameters. Future study will focus on time series deformation modelling, considering concrete inner and external coefficients, such as temperature, humidity, and rheological parameters.

Author Contributions: X.X. designed the experiment. Y.Z. carried out the experiment. X.X. and Y.Z. analyzed the experimental results. L.C., Z.Y. and P.T. participated in the discussion of the experimental conclusion. Y.Z. wrote the manuscript of the paper. All the authors contributed to the revision of the manuscript, reviewed and approved the manuscript.

Funding: This work was supported by the National Natural Science Foundation (No: 41701536, 61701047, 41674040) of China, Natural Science Foundation of Hunan Province (No. 2017JJ3322, 2019JJ50639), Key Project of Education Department of Hunan Province (No. 18A148), the Key Laboratory of Special Environment Road Engineering of Hunan Province (No. kfj130405), and the Open Fund of Key Laboratory of Road Structure and Material of Ministry of Transport (No. kfj090209).

Acknowledgments: The TerraSAR-X satellite images used in this paper are provided by the German Space Center (DLR) (Data Order Program Project: MTH3393). Thanks for Professor Junhui Zhang of Transportation Engineering 
College for providing the leveling deformation data of Lungui Highway, which provides available validation data for this paper.

Conflicts of Interest: The authors declare no conflict of interest.

\section{References}

1. Bergado, D.T.; Ahmed, S.; Sampaco, C.L.; Balasubramaniam, A.S. Settlements of Bangna-Bangpakong highway on soft Bangkok clay. J. Geotech. Eng. 1990, 116, 136-155. [CrossRef]

2. Shi, X.; Liao, M.S.; Teng, W.; Lu, Z.; Wei, S.; Wang, C.J. Expressway deformation mapping using high-resolution TerraSAR-X images. Remote Sens. Lett. 2014, 5, 194-203. [CrossRef]

3. Mousavi, S.M.; Shamsai, A.; Naggar, M.H.E.; Khamehchian, M. A GPS-based monitoring program of land subsidence due to groundwater withdrawal in Iran. Can. J. Civ. Eng. 2001, 28, 452-464. [CrossRef]

4. Lanari, R.; Mora, O.; Manunta, M.; Mallorqui, J.J. A small-baseline approach for investigating deformations on full-resolution differential SAR interferograms. IEEE Trans. Geosci. Remote Sens. 2004, 42, 1377-1386. [CrossRef]

5. Berardino, P.; Fornaro, G.; Lanari, R.; Sansosti, E. A new algorithm for surface deformation monitoring based on small baseline differential SAR interferograms. IEEE Trans. Geosci. Remote Sens. 2003, 40, 2375-2383. [CrossRef]

6. Chen, J.; Zeng, Q.M.; Jiao, J.; Zhao, B.C. SBAS time series analysis technique based on Sentinel-1A TOPS SAR images: A case study of Yellow River Delta. Remot. Sens. Land Resour. 2017, 29, 82-87. (In Chinese) [CrossRef]

7. Lanari, R.; Berardino, R.; Bonano, M.; Casu, F.; Luca, C.D.; Elefante, S.; Fusco, A.; Manunta, M.; Manzo, M.; Ojha, C. Sentinel-1 results: SBAS-DInSAR processing chain developments and land subsidence analysis. In Proceedings of the 2015 IEEE International Geoscience and Remote Sensing Symposium (IGARSS), Milan, Italy, 26-31 July 2015.

8. Corsetti, M.; Fossati, F.; Manunta, M.; Marsella, M. Advanced SABS- DInSAR technique for controlling large civil infrastructures: an application to the genzano di lucania dam. Sensors 2018, 18, 2371. [CrossRef] [PubMed]

9. Papoutsis, I.; Papanikolaou, X.; Floyd, M.; Ji, K.H.; Kontoes, C.; Zacharis, V. Mapping infation at Santorini volcano, Greece, using GPS and InSAR. Geophys. Res. Lett. 2013, 40, 267-272. [CrossRef]

10. Hooper, A.; Bekaert, D.; Spaans, K.; Arikan, M. Recent advances in SAR interferometry time series analysis for measuring crustal deformation. Tectonophysics 2011, 514, 1-13. [CrossRef]

11. Tolomei, C.; Taramelli, A.; Moro, M.; Saroli, M.; Aringoli, D.; Salvi, S. Analysis of the deep-seated gravitational slope deformations over Mt. Frascare (Central Italy) with geomorphological assessment and DInSAR approaches. Geomorphology 2013, 201, 281-292. [CrossRef]

12. Zhi, W.L.; Yang, Z.F.; Jian, J.Z.; Hu, J.; Yun, J.W.; Pei, X.L.; Guo, L.C. Retrieving three-dimensional displacement fields of mining areas from a single InSAR pair. J. Geod. 2015, 89, 17-32. [CrossRef]

13. Solari, L.; Ciampalini, A.; Raspini, F.; Bianchini, S.; Zinno, I.; Bonano, M.; Casagli, N. Combined use of C-and $X-B a n d ~ S A R$ data for subsidence monitoring in an urban area. Geosciences 2017, 7, 21. [CrossRef]

14. Han, Y.F.; Song, X.G.; Shan, X.J.; Qu, C.Y.; Wang, C.S.; Guo, L.M.; Zhang, G.F.; Liu, Y.H. Deformation monitoring of Changbaishan Tianchi volcano using D-InSAR technique and error analysis. Chin. J. Geophys. 2010, 53, 1571-1579. [CrossRef]

15. Goldstein, R.M.; Engelhardt, H.; Kamb, B.; Frolich, R.M. Satellite radar interferometry for monitoring ice sheet motion: Application to an antarctic ice stream. Science 1993, 262, 1525-1530. [CrossRef] [PubMed]

16. Li, J.; Li, Z.W.; Ding, X.L.; Wang, Q.J.; Zhu, J.J.; Wang, C.C. Investigating mountain glacier motion with the method of SAR intensity-tracking: Removal of topographic effects and analysis of the dynamic patterns. Earth Sci. Rev. 2014, 138, 179-195. [CrossRef]

17. Xu, W.B.; Bürgmann, B.; Li, Z.W. An improved geodetic source model for the $1999 \mathrm{Mw} 6.3$ Chamoli earthquake, India. Geophys. J. Int. 2016, 205, 236-242. [CrossRef]

18. Mirzaee, S.; Motagh, M.; Akbari, B.; Wetzel, H.; Roessner, S. Evaluating three InSAR time-series methods to assess creep motion, Case study: Masouleh landslide in North Iran. ISPRS Ann. Photogramm. Remote Sens. Spat. Inf. Sci. 2017, 223-228. [CrossRef] 
19. Bayer, B.; Simoni, A.; Schmidt, D.; Bertello, L. Using advanced InSAR techniques to monitor landslide deformations induced by tunneling in the Northern Apennines, Italy. Eng. Geol. 2017, 226, 20-32. [CrossRef]

20. Sun, Q.; Zhang, L.; Ding, X.L.; Hu, J.; Li, Z.W.; Zhu, J.J. Slope deformation prior to Zhouqu, China landslide from InSAR time series analysis. Remote Sens. Environ. 2015, 156, 45-57. [CrossRef]

21. Wang, C.; Zhang, Z.; Zhang, H.; Wu, Q.; Zhang, B.; Tang, Y. Seasonal deformation features on Qinghai-Tibet railway observed using time-series InSAR technique with high-resolution TerraSAR-X images. Remote Sens. Lett. 2017, 8, 1-10. [CrossRef]

22. Zhao, R.; Li, Z.W.; Feng, G.C.; Wang, Q.J.; Hu, J. Monitoring surface deformation over permafrost with an improved SBAS-InSAR algorithm: With emphasis on climatic factors modeling. Remote Sens. Environ. 2016, 184, 276-287. [CrossRef]

23. Lundgren, P.; Usai, S.; Sansosti, E.; Lanad, R.; Tesauro, M.; Fornaro, G.; Berardino, P. Modeling surface deformation observed with Synthetic Aperture Radar Interferometry at Campi Flegrei Caldera. J. Geophys. Res. 2001, 106, 19355-19366. [CrossRef]

24. Usai, S. A least-squares approach for long-term monitoring of deformations with differential SAR interferometry. In Proceedings of the IEEE International Geoscience \& Remote Sensing Symposium, Toronto, ON, Canada, 24-28 June 2002.

25. Béjar-Pizarro, M.; Ezquerro, P.; Herrera, G.; Tomás, R.; Guardiola-Albert, C.; Hernández, J.M.; Merodo, J.F.; Marchamalo, M.; Martinez, R. Mapping groundwater level and aquifer storage variations from InSAR measurements in the Madrid aquifer, Central Spain. Hydrogol. J. 2017, 547, 678-689. [CrossRef]

26. Lauknes, T.R.; Howard, A.Z.; Yngvar, L. InSAR deformation time series using an L1-Norm small-baseline approach. IEEE Trans. Geosci. Remote Sens. 2011, 49, 536-546. [CrossRef]

27. Lanari, R.; Casu, F.; Manzo, M.; Lundgren, P. Application of the SBAS-DInSAR technique to fault creep: A case study of the Hayward fault, California. Remote Sens. Environ. 2007, 109, 20-28. [CrossRef]

28. Manunta, M.; Marsella, M.; Zeni, G.; Sciotti, M.; Atzori, S.; Lanari, R. Two-scale surface deformation analysis using the SBAS-DInSAR technique: A case study of the city of Rome, Italy. Int. J. Remote Sens. 2008, 29, 1665-1684. [CrossRef]

29. Arangio, S.; Calò, F.; Mauro, M.D.; Bonano, M.; Marsella, M.; Manunta, M. An application of the SBAS-DInSAR technique for the assessment of structural damage in the city of Rome. Struct. Infrastruct. Eng. 2014, 10, 1469-1483. [CrossRef]

30. Zhou, L.; Guo, J.; Hu, J.; Li, J.; Xu, Y.; Pan, Y.; Shi, M. Wuhan surface subsidence analysis in 2015-2016 based on Sentinel-1a data by SBAS-InSAR. Remote Sens. 2017, 9, 982. [CrossRef]

31. Li, S.S.; Li, Z.W.; Hu, J.; Sun, Q.; Yu, X.Y. Investigation of the seasonal oscillation of the permafrost over Qinghai-Tibet Plateau with SBAS-InSAR algorithm. Chin. J. Geophys. 2013, 56, 1476-1486. (In Chinese)

32. Kampes, B.M.; Hanssen, R.F. Ambiguity resolution for permanent scatterer interferometry. IEEE Trans. Geosci. Remote Sens. 2004, 42, 2446-2453. [CrossRef]

33. Funning, G.J.; Bürgmann, R.; Ferretti, A.; Novali, F.; Fumagalli, A. Creep on the Rodgers Creek Fault, northern San Francisco Bay area from a 10 year PS-InSAR dataset. Geophys. Res. Lett. 2007, 34, 255-268. [CrossRef]

34. Ferretti, A.; Fumagalli, A.; Novali, F.; Prati, C.; Rocca, F.; Rucci, A. A New Algorithm for Processing Interferometric Data-Stacks: SqueeSAR. IEEE Trans. Geosci. Remote Sens. 2011, 49, 3460-3470. [CrossRef]

35. Salichon, J.; Delouis, B.; Lundgren, P.; Giardini, M.; Costantini, M.; Rosen, P. Joint inversion of broadband teleseismic and interferometric synthetic aperture radar (InSAR) data for the slip history of the Mw $=7.7$, Nazca ridge (Peru) earthquake of 12 November 1996. J. Geophys. Res.-Solid Eaeth 2003, 108. [CrossRef]

36. Costantini, M.; Rosen, P.A. Generalized phase unwrapping approach for sparse data. In Proceedings of the IEEE International Geoscience \& Remote Sensing Symposium, Hamburg, Germany, 28 June-2 July 1999.

37. Xing, X.M.; Wen, D.; Chang, H.-C.; Chen, L.F.; Yuan, Z.H. Highway deformation monitoring based on an integrated CRInSAR algorithm-Simulation and real data validation. Int. J. Pattern Recognit. Artif. Intell. 2018, 32. [CrossRef]

38. Roberto, T.; Yolanda, M.; Lopez-Sanchez, J.M.; José, D.; Blanco, P.; Jordi, J.M. Mapping ground subsidence induced by aquifer overexploitation using advanced Differential SAR Interferometry: Vega media of the Segura River (SE Spain) case study. Remote Sens. Environ. 2005, 98, 269-283. [CrossRef]

39. Burbey, T.J. The influence of Geologic Structures on Deformation due to Ground Water Withdrawal. Ground Water 2008, 46, 202-211. [CrossRef] 
40. Hoffmann, J.; Zebker, H.A.; Galloway, D.L.; Amelung, F. Seasonal subsidence and rebound in Las Vegas Valley, Nevada, observed by synthetic aperture radar interferometry. Water Resour. Res. 2001, 37, 1551-1566. [CrossRef]

41. Bell, J.W.; Amelung, F.; Ferretti, A.; Bianchi, M.; Novali, F. Permanent Scatterer InSAR reveals seasonal and long-term aquifer-system response to groundwater pumping and artificial recharge. Water Resour. Res. 2008, 44. [CrossRef]

42. Wroblicky, G.J.; Campana, M.E.; Valett, H.M.; Dahm, C.N. Seasonal variation in Surface-subsurface water exchange and Lateral Hyporheic area of two stream-aquifer system. Water Resour. Res. 1998, 34, 317-328. [CrossRef]

43. Segal, D.C.; Moran, J.E.; Visser, A.; Singleton, M.J.; Esser, B.K. Seasonal variation of high elevation groundwater recharge as indicator of climate response. J. Hydrol. 2014, 519, 3129-3141. [CrossRef]

44. Hanssen, R.F. Radar Interferometry: Data Interpretation and Error Analysis; Kluwer Academic Publishers: New York, NY, USA, 2001.

(C) 2019 by the authors. Licensee MDPI, Basel, Switzerland. This article is an open access article distributed under the terms and conditions of the Creative Commons Attribution (CC BY) license (http://creativecommons.org/licenses/by/4.0/). 